\title{
LA RESPONSABILIDAD DE LOS DAÑOS CAUSADOS POR ANIMALES EN LAS PERSONAS EN LOS TEXTOS ROMANOS Y EN CODIGOS MEDIEVALES ESPAÑOLES
}

\author{
Olga Marlasca Martínez
}

\section{Introducción}

Los casos frecuentes de daños producidos por determinados animales cuadrúpedos, fundamentalmente perros, y el eco que ello origina en los medios de comunicación actuales cuando se producen estos actos, nos han motivado para estudiar en el presente trabajo la regulación de los daños causados por animales en las personas, fundamentalmente en su perspectiva histórica, comenzando naturalmente con la regulación de los citados daños en el derecho romano.

Sin entrar en este momento en más pormenores hay que decir que el principio de la responsabilidad del dueño del animal por los actos realizados por éste, ha sido reconocido por todas las legislaciones, desde la romana hasta la actual legislación española ${ }^{1}$, pasando evidentemente por

${ }^{1}$ El artículo 1.905 del C.C., establece: El poseedor de un animal o el que se sirve de él, es responsable de los perjuicios que causare, aunque se les escape o extravíe. Sólo cesará esta responsabilidad en el caso de que el daño proviniera de fuerza mayor o de culpa del que lo hubiese sufrido. En fechas muy recientes se ha aprobado la Ley sobre el Régimen Jurídico de la tenencia de animales potencialmente peligrosos (Ley de 23 dic. 1999). En la Exposición de Motivos de la citada ley se establece, entre otras cosas, que, diversos ataques a personas, protagonizados por perros, han generado un clima de inquietud social y obligan a establecer una regulación que permita controlar y delimitar el régimen de tenencia de perros potencialmente peligrosos. Además, el artículo 1 dice lo siguiente: La presente Ley tiene por objeto establecer la normativa aplicable a la tenencia de animales potencialmente peligrosos para hacerla compatible con la seguridad de personas y bienes y de otros animales. Por otra parte, el Código Penal de 1995 establece en el artículo 631 lo siguiente: Los dueños o encargados de la custodia de animales feroces o dañinos que los dejaren sueltos o en condiciones de causar mal, serán castigados con la pena de multa de quince a treinta días. Hay que decir acerca del citado artículo que se castiga la sola creación del riesgo. Por otra parte, los adjetivos de «feroz o dañino» no determinan, necesariamente, que el animal tenga que ser salvaje. El animal doméstico o el domesticado puede resultar igualmente fiero o dañino en ciertas situaciones o circunstancias. 
las legislaciones intermedias, en los términos a los que nos vamos a referir en los siguientes apartados.

De esta manera en las presentes líneas se pretende mostrar el iter que ha recorrido la regulación jurídica de los citados daños, desde su origen en el derecho romano, a través de determinados textos jurídicos que constituyen el denominado derecho histórico español.

Así pues, la disposición y división del trabajo se estructura en los siguientes apartados: en primer lugar, se muestran las líneas generales de la regulación romana acerca de los daños causados por animales; a ellos hacen alusión, concretamente determinados textos del Digesto de Justiniano, así como el texto correspondiente que se recoge en las Pauli Sententiae ${ }^{2}$. En el siguiente apartado se presenta el estudio de los daños mencionados en la Lex Visigothorum ${ }^{3}$, fundamentalmente determinadas disposiciones contenidas en LV 8,4: de damnis animalium (vel diversorum rerum), teniendo en cuenta la importancia que la LV como cuerpo legal tuvo posteriormente en la Edad Media española; al final de cada disposición de la LV se incluye la versión de la misma contenida en el Fuero Juzgo ${ }^{4}$. Asimismo, se muestran algunos testimonios acerca de

${ }^{2}$ Las Pauli Sententiae son citadas en la edición propuesta en Fontes Iuris Romani Anteiustiniani FIRA. Vol. I, Leges, ed. S. Riccobono (1941), (nueva ed. 1968), II, Auctores ed. Bavier e I. Furlani (1940, nueva ed. 1964); III, Negotia, ed. ARANGIo RuIZ (1943, nueva ed. con apéndice, Florentiae, 1968).

${ }^{3}$ La Lex Visigothorum, conocida también con los nombres de Liber Iudicum o Liber Iudiciorum, es un libro destinado a la práctica forense y consiste en una recopilación de las leyes promulgadas por los monarcas visigodos que lleva a cabo Recesvinto en el año 654. Las leyes del Liber en la forma recesvindiana que ha llegado hasta nosotros - aunque no todas, pues hay alguna excepción - van precedidas de una de las siguientes inscripciones: Antiqua, Flavius Recaredus Rex, Flavius Sisebutus Rex, Flavius Chindasvintus Rex, Flavius Gloriosus Reccesvintus Rex. De forma que, por un lado, recoge leyes cuyos autores aparecen mencionados; y de otro, leyes que estaban recogidas ya en libros. Las leyes que proceden de recopilaciones llevan la rúbrica antiqua; si los redactores las corrigieron, las colocaron bajo la rúbrica de antiqua enmendata. Un resumen de la historia de la legislación visigótica de Eurico a Witiza puede verse en ZeUMER, Historia de la legislación, trad. esp. por Carlos Clavería (Barcelona, 1944), 64 ss. UReÑa y SMENJAud, La legislación gótico-hispana (Leges Antiquiores-Liber Iudiciorum). Estudio crítico (Madrid, 1905), pp. 45 y ss. También IgLESIA Ferreiros, La creación del Derecho. Una historia de la formación de un derecho estatal español (Barcelona, 1992). Puede verse en el citado autor un estudio del proceso de la formación de la legislación visigoda.

4 Pocos años después de la aparición del código de Recesvinto se sintió ya la necesidad de acometer una nueva reforma. La revisión del Liber se lleva a cabo en la época de Ervigio (680-687) y lo promulga el monarca citado el año 681. El sucesor de Ervigio, Egica intentó realizar una nueva redacción pero no se tiene constancia de que la misma llegara a materializarse, aunque se añadieron leyes suyas a los ejemplares oficia- 
los daños causados por animales que se recogen en determinados fueros municipales hispanos. A continuación, nos referimos a la recepción del derecho romano y, en primer lugar, presentamos algunas observaciones generales acerca del ius commune en Europa y en particular en algunos territorios hispánicos, teniendo en cuenta la importancia del citado derecho en los textos medievales españoles, entre otros. Finalmente, en el mismo apartado acerca de la recepción, hacemos mención a las disposiciones de los textos legales medievales (fundamentalmente el Fuero Real y las Siete Partidas) que son objeto de la recepción del ius commune y que tienen relación con el tema objeto de nuestro estudio.

\section{La regulación en los textos romanos}

\subsection{Consideraciones previas}

Dentro del iter que recorren determinadas instituciones jurídicas a través de diversos textos legales, abordamos, en primer lugar, el estudio de los textos jurídicos romanos. Al estudiar Mommsen ${ }^{5}$ en el capítulo

les de la Lex Visigothorum. A partir de finales del s. VII, juristas anónimos añaden a la LV leyes de Recesvinto que no fueron tenidas en cuenta en la edición recesvindiana de la citada Lex, además de modificaciones y añadidos en los textos legales. Todas estas transformaciones sufridas por la edición ervigiana dan lugar a lo que se conoce con el nombre de redacción Vulgata de la LV y han sido objeto de estudio por GARCía LÓPEZ, Y., Estudios críticos y literarios de la Lex Visigothorum (Santiago de Compostela, 1991), pp. 75-475. Finalmente hay que decir que en el s. XIII se traduce la LV al castellano con el nombre de Fuero Juzgo. Sobre el citado texto legal, puede verse una obra que sigue siendo especialmente útil de FERnÁNDEZ LleRA, F., Gramática y vocabulario del Fuero Juzgo (Madrid, 1930).

5 Mommsen, T., Derecho penal romano, trad. del alemán por P. Dorado (Bogotá, 1976), pp. 498 y ss. Según el autor se trata de una serie de acciones derivadas de delitos, las cuales no caían dentro del círculo de los daños a la propiedad sancionados por la ley Aquilia, pero que sin embargo eran consideradas y sentenciadas de un modo más o menos análogo a las aquilianas y se referían a los delitos siguientes: $1 .^{\circ}$. Daños de animales, según las Doce Tablas. 2. ${ }^{\circ}$ Derribo de árboles frutales, según las Doce Tablas. 3. ${ }^{\circ}$ Homicidio culposo de hombres libres, según el derecho honorario. $4 .^{\circ}$ Lesión corporal de hombres libres, según el derecho honorario. 5. ${ }^{\circ}$ Incendio, según las Doce Tablas. $6 .^{\circ}$ Abuso de la adstipulación, según la ley Aquilia. 7. ${ }^{\circ}$ Corrupción moral de las personas sometidas a la potestad doméstica, según el derecho honorario. 8. ${ }^{\circ}$ Daños por tener animales peligrosos, según el derecho honorario. $9 .^{\circ}$ Daños por echar o tirar algo, según el derecho honorario. $10 .^{\circ}$ Lesiones corporales cualificadas y daño en las cosas, según el derecho imperial. 
correspondiente a la responsabilidad por los daños que han sido causados (daños en los templos, daños en los sepulcros, daños en la propiedad pública, daños en la propiedad privada, esto es, damnum iniuria), se refiere a continuación el autor citado a las acciones por daños análogas a las estudiadas, entre otras, concretamente: daños producidos por animales, según las Doce Tablas y daños por tener animales peligrosos, según el derecho honorario.

Por lo que respecta al daño causado por un animal perteneciente a la propiedad privada de alguien, según establece Mommsen ${ }^{6}$, no estaba considerado por el derecho de las Doce Tablas, ni tampoco por el de los tiempos posteriores, como caso de «injusticia», esto es, de iniuria $^{7}$, pero sí como caso de pastoreo abusivo, pauperies $^{8}$, y en tal concepto se le trataba como delito semejante a la iniuria. Además, se consideraba como modos de la pauperies, igual que sucedía en un principio con la iniuria, tanto el daño que el animal causara en el cuerpo de una persona, como el que causara en las cosas. Según el citado autor ${ }^{9}$, a los animales se les consideraba enteramente lo mismo que a los hombres, sujetos a la organización social; se hacían merecedores de castigo siempre que pacieran ilícitamente; si luchando dos animales se hacían daño uno de ellos, se hacía según esto merecedor de pena aquel que hubiese dado comienzo a la lucha: cuando el animal fuera conducido por un hombre, sólo a éste se le hacía responsable. De manera que el antiquísimo concepto de pauperies abarcaba el daño causado por un animal en el cuerpo o en los bienes de alguna persona ${ }^{10}$.

${ }^{6}$ Vid. sobre el particular, Mommsen, Derecho penal romano, p. 513.

7 Lo opuesto al derecho, ius, no en su sentido ético, sino en el político, era en Roma la injusticia, iniuria. Esta derivación de la palabra responde al sentido esencialmente negativo en que principalmente se hacía uso de ella, limitándolo a las relaciones reguladas por el Estado. Pero técnicamente se daba a dicha voz un significado más restringido, aplicándola con sentido positivo a las ofensas causadas a un tercero en su cuerpo o en sus cosas, en contraposición a la apropiación ilgítima de cosas ajenas, o sea el furtum. Como consecuencia de esta contraposición, al desarrollarse posteriormente el derecho, se dividió la iniuria en iniuria simplemente, o sea ofensa antijurídica causada a la persona, y damnum iniuria, o daño causado injustamente en las cosas, partiendo, al efecto, de la idea de que, en el primer caso, no se debía atender sino a la imposición de penas, mientras en el segundo había que procurar, ante todo, la indemnización del daño. En esto estribaba la tripartición del delito privado, vid. Mommsen, Derecho penal romano, p. 484.

8 Pauperies es el daño causado sin culpa del que lo hace, porque un animal no puede haberlo hecho con injuria, porque carece de razón, cf. Dig. 9,1,1,3.

9 Vid. Mommsen, Derecho penal romano, p. 513.

10 Ibidem, p. 507. 


\subsection{Textos legales que se refieren a los daños causados por animales}

En el derecho romano, como es sabido, el delito de daño injustamente causado (damnum iniuria dutum) ${ }^{11}$ procede de la lex Aquilia de damno, plebiscito propuesto por el tribuno Aquilio, probablemente del año 286 a.C. ${ }^{12}$. Este delito es importante por las numerosas decisiones jurisprudenciales que elaboran la noción de culpa o negligencia en relación con él y la gran influencia que ha tenido en la moderna doctrina de la responsabilidad extracontractual o aquiliana ${ }^{13}$.

Además, según establece el texto de Ulpiano en Dig. 9,2,1 ${ }^{14}$, la ley Aquilia derogó las leyes precedentes que trataban del daño injusto, tanto las contenidas en las XII Tablas como otras, pero dejó en vigor algunas acciones privadas ${ }^{15}$ para reclamación o indemnización del daño causado. Una de estas acciones es la actio de pauperie que se concede por daños causados por animales cuadrúpedos y cuya regulación está contenida en el Dig. 9,1, bajo la rúbrica: si quadrupes pauperiem fecisse dicatur.

Hechas estas precisiones, nos vamos a referir a continuación a una serie de acciones derivadas de determinados delitos, los cuales no caían dentro del círculo de los daños a la propiedad sancionados por la ley Aquilia: en primer lugar, los daños causados por cuadrúpedos, regulados por la actio de pauperie y, además, los daños por tener animales peligrosos, según el derecho honorario.

\subsubsection{Daños regulados por la actio de pauperie}

La acción específica para el caso de los daños causados por animales cuadrúpedos es la actio de pauperie; procede ejercitar la cita-

11 Se trata del delito de daños en las cosas, damnum iniuria, que consistía en destruir una cosa ajena o mermar su valor, sin tener derecho para ello. Estos daños a la propiedad eran sancionados por la ley Aquilia. Pero además existían una serie de acciones derivadas de delitos y que eran consideradas y sentenciadas de un modo más o menos análogo a la acción aquiliana.

12 Se regula fundamentalmente en el Digesto de Justiniano, concretamente en Dig. 9,2, bajo la rúbrica: Ad legem Aquiliam.

13 Vid. GARCía GARRIDO, Derecho privado romano. Acciones, casos, instituciones. $4 .^{\mathrm{a}}{ }^{\mathrm{ed}}$. reformada (Madrid, 1988), pp. 441-442.

${ }^{14}$ Se trata de un texto de Ulpiano de los Comentarios al Edicto, libro 18 contenido en Dig. 9,2,1, donde se establece: Lex Aquilia omnibus legibus, quae ante se de damno iniuria locutae sunt, derogavit, sive duodecim tabulis, sive alia quae fuit; quas leges nunc referre non est necesse.

15 Algunas acciones privadas que la ley Aquilia dejó subsistentes son, además de la $a c$ tio de pauperie, Ia actio aquae pluvia arcendae y la actio de pastu pecoris contra la immissio de ganado para pastar en fundo ajeno, cf. D'ORs, A., Derecho romano privado (Pamplona, 1986), pp. 427-428. 
da actio por los daños causados por los animales mencionados, la cual sigue el régimen noxal ${ }^{16}$ en el sentido de que el propietario puede exonerarse de responsabilidad entregando el animal que causó el daño.

Precisamente sobre la idea que sirve de fundamento a la responsabilidad noxal se basa el concepto de responsabilidad por daños causados por los animales ${ }^{17}$. Veamos además, brevemente, lo que ocurría, en relación con las acciones noxales, tratándose de daños causados por esclavos e hijos de familia. Hay que tener en cuenta que el derecho clásico concedió acciones delictuales por los delitos de los esclavos e hijos de familia con una fórmula peculiar, dirigida, alternativamente, al pago de una indemnización en concepto de pena o a la entrega del ofensor, noxae deditio (actiones noxales). El demandado con una acción de esta clase que, ante el pretor, reconocía ser padre o dueño del autor del delito, podía evitar el proceso entregando éste, por mancipatio, al ofendido. Pero si optaba por defenderlo y sucumbía en el proceso, era condenado, alternativamente, al pago de la indemnización o a la noxae deditio ${ }^{18}$.

Por otra parte, la acción noxal sólo alcanzaba al padre o dueño en su cualidad de tal. La responsabilidad por el hecho no pesaba sobre él, sino sobre el hijo o el esclavo, de manera que seguía a éste después de pasar a la potestad de otra persona (noxa caput sequitur): si el esclavo era enajenado a un tercero o el hijo adoptado por otro, la acción desde el instante de la enajenación o la adopción, había de ser dirigida contra el nuevo dueño o el adoptante. Al salir el hijo de la potestad paterna o el esclavo de la dominical (por ej., por emancipación o manumisión), la acción noxal desaparecía y el perjudicado sólo se podía dirigir directamente contra el autor del delito ${ }^{19}$.

Por lo que respecta a nuestro tema de estudio hay que decir que los principios de la responsablilidad noxal eran aplicables a los daños producidos por animales ya que, según Kunkel ${ }^{20}$, el derecho de venganza primitiva podía tener también por objeto el actor animal.

16 La responsabilidad noxal, tratándose de daños de animales, concede al dueño del mismo la opción entre la entrega del animal a quien sufrió los daños (in noxam dare) y la indemnización pecuniaria del daño causado (noxiam sarcire), entre otros, KASER, Derecho privado romano. Trad. esp. por Santa Cruz Teijeiro. (Madrid, 1968), p. 227.

17 Vid. KASER, Derecho privado romano, p. 227.

18 Véase, entre otros, Jörs-KunKel, Derecho privado romano. Trad. esp. por Prieto Castro (Barcelona, 1965), p. 383.

19 Vid., entre otros, JöRS-KUNKEL, Derecho privado romano, pp. 383-384.

20 KUNKEL, Derecho privado romano, p. 384. 
La acción que en estos casos se concedía era necesariamente noxal y quedaba extinguida por la muerte ${ }^{21} \mathrm{del}$ animal; noxae dedere est animal tradere vivum, establece el texto de Ulpiano en Dig. 9,1,1422 y por tanto: plane si ante litem contestatam decesserit animal, extincta erit $a$ tio $^{23}$. Sólo en el caso de que el propietario del animal negara pertenecerle la posesión, es cuando perdía el derecho de librarse de la acción entregando el animal. Por otra parte, por lo que respecta al principio noxa caput sequitur, citado supra, y que tiene relación asimismo con los animales, hace alusión al mismo el texto contenido en Dig. 9,1,12, ${ }^{24}$ de manera que se da esta acción contra el dueño del cuadrúpedo que lo es en el momento, no de cometerse el daño, sino cuando se interpone la acción ${ }^{25}$.

Por lo que respecta al origen de la citada acción, ya el texto de las XII Tablas $(8,6)$ conoce una actio de pauperie que impone al dueño de un animal doméstico ${ }^{26}$ que causa un daño, la opción entre la entrega del animal al que lo sufrió (in noxam dare) y la indemnización pecuniaria del daño causado (noxiam sarcire) ${ }^{27}$. En el Digesto de Justiniano, los daños a los que nos referimos y los supuestos de aplicación de la actio pauperie se regulan fundamentalmente, como se ha dicho supra, en Dig. 9,1. Concretamente, a la citada actio que procede del texto decemviral como

${ }^{21}$ En relación con las acciones noxales, sostiene D’ORS, «En torno a la llamada obligación alternativa», en Revista de Derecho Privado (1944), 22, la afirmación de que en las mismas - tanto antes como después de la litis contestatio - no hay más que facultas solutionis y no alternatividad. Tal régimen consiste en que cuando comete un delito un animal cuadrúpedo (incluyendo el perro, en virtud de la lex Pesolania: Pauli Sententiae 1,15,1, el dueño del mismo, si puede (si el animal murió, no hay obligación) entregar dicho animal, debe indemnizar el daño (facultas solutionis), de no preferir entregarlo (lo mismo que con los delitos de hijos y de esclavos): aut noxam sarcire aut in noxam dare. La obligación principal es la de dar, y facultativa la otra (ya que no hay obligación si la entrega se hace imposible). La misma afirmación acerca de las acciones noxales es reiterada por el citado autor en Miscelánea, AHDE, 17 (1946), p. 923.

22 Estableciéndose, además, en el texto de Dig. 9,1,14 que si el animal fuera común de muchos, la acción noxal será por el todo contra cada uno, como respecto de un esclavo.

23 Cf. Dig. 9,1,13.

${ }^{24}$ El texto de Ulpiano de los comentarios al Edicto, libro 18 en este caso en Dig. 9,1,12, establece: et quum etiam in quadrupedibus noxa caput sequitur, adversus dominum haec actio datur, non cuius fuerit quadrupes, quum noceret, sed cuius nunc est.

${ }_{25}$ En todo lo demás esta acción se hallaba sometida a las reglas de la acción aquiliana, cf. Mommsen, Derecho penal romano, p. 513.

26 Probablemente las Doce Tablas estimaban como cuadrúpedos sólo animales domésticos: caballos, vacas, cabras, etc. y hasta parece que el precepto se extendió a los perros por una ley especial (puede ser la lex Pesolania, en PS 1,15,1. Sobre el particular, KUNKEL, p. 384.

27 KASER, Derecho privado romano, p. 227. 
acabamos de mencionar, se refiere el texto de Ulpiano contenido en Dig. $9,1,1$ pr. $^{28}$.

Asimismo, otro texto del citado jurista, contenido en este caso, en Dig. $9,1,1,4,{ }^{29}$ alude a un fragmento de $\mathrm{Servio}^{30}$, perteneciente a un libro o lugar desconocido que se ha conservado en el libro 18 de los Comentarios al Edicto del Pretor de Ulpiano donde nos dice que tiene lugar esta acción en una serie de supuestos.

El mencionado fragmento contiene una delimitación de los actos imputables a la ferocidad del animal secundum natura y aquellos otros en los que la fuerza impulsiva, externa, se ejerce sobre el cuadrúpedo en modo tal que de no producirse no habrían existido los daños. Más concretamente, en la primera parte del texto de Ulpiano puede afirmarse con propiedad que los perjuicios los ha ocasionado el animal; mientras que en los supuestos que menciona a continuación se le puede imputar responsabilidad a una persona. Esto es, el núcleo del problema está en lo que establece el texto: quum commota feritate nocuit cuadrupes, sea como consecuencia natural y directa de su intrínseca ferocidad, que se manifiesta en una situación propia para ello, o ya se origine por una actuación extraña a él ${ }^{31}$.

De manera que en los diferentes textos de Ulpiano en la citada sede del Digesto (Dig.9,1), podemos distinguir, por una parte:

a) Daños causados propter naturalem feritatem. Así, concretamente, el texto citado de Ulpiano contenido en Dig. 9,1,1,4 recoge una serie de hechos frecuentes: 1 . La coz propinada por un caballo coceador: si equus calcitrosus calce percusserit. 2 . La cornada producida por la embestida de un buey: si bos cornu petere

${ }^{28}$ El texto de Ulpiano de los Comentarios al Edicto, en el libro 18, contenido en Dig. 9,1,1, pr., establece:

Si quadrupes pauperiem fecisse dicetur, actio ex lege duodecim tabularum descendit; quae lex voluit aut dari id, quod nocuit, id est id animal, quod noxiam commisit, aut aestimationem noxiae oferri.

29 Dig. 9,1,1,4 que establece: itaque, ut Servias scribit, tunc haec actio locum habet, quum commota feritate nocuit quadrupes, puta si equus calcitrosus calce percusserit, aut bos cornu petere solitus petierit, aut mulae porter nimiam ferociam. Quodsi propter loci iniquitatem, aut propter culpam mulionis, aut si plus iusto onerata quadrupes in aliquem onus everterit, haec actio cessabit, damnique iniurae agetur.

30 Servio Sulpicio Rufo, contemporáneo y gran amigo de Marco Tulio Cicerón, que le tributa laudes en su Bruto: in iure civili esse princeps, hasta el punto de inquirir: etiamne Scaevola, Servium nostrum anteponis (Brutus, 41, 151 a 153), ha dejado dos textos recogidos en el Digesto, transmitidos por Ulpiano.

31 Cf. sobre el particular, MARTínEZ SARRIón, A., Las raíces romanas de la responsabilidad por culpa (Barcelona, 1993), p. 445. 
solitus petierit. 3. Las mulas demasiado fieras: si mulae propter nimiam ferociam. Hay que destacar que el empleo del si en estos supuestos indica su carácter de meros ejemplos. Aludimos asimismo a lo que se establece en otro apartado: 4. Y en general, tiene lugar esta acción, por reacción de la misma naturaleza del animal, así, en otro texto de Ulpiano en Dig. 9,1,1,732, Este criterio general se aplicaría a la variada gama de daños causados por animales domésticos sobre los que recae directamente la responsabilidad del resultado perjudicial ${ }^{33}$. La acción pertinente en estos casos es la actio de pauperie, citada supra.

b) Daños provocados por imprevisión, culpa o negligencia. Si se dan estas circunstancias no tiene aplicación la actio de pauperie, y por tanto la específica para todos ellos es la actio legis Aquiliae. Concretamente, enumera Servio ${ }^{34}$ una serie de supuestos: 1) Por lo inapropiado del lugar en que se hace transitar al animal: si propter loci iniquitatem. 2) Por culpa del mulero: si propter culpam mulionis. 3) Por la carga excesiva: si plus iusto onerata quadrupes in aliquem onus everterit. Son hechos de los que puede decirse que el protagonismo ha dejado al animal para pasar al hombre; aunque el daño lo ha causado materialmente la bestia, la causa relevante ha sido la imprudencia o imprevisión del hombre ${ }^{35}$.

Por otra parte, hay que tener asimismo en cuenta que, en Dig. 9,1,1,636 se establece que no tiene aplicación la actio de pauperie, aunque se produzcan daños, en el caso de hostigamiento del animal por persona que no es el dueño. Ahora bien, si quum equum permulsisset quis vel palpatus esset, calce eum percusserit, erit actioni locus ${ }^{37}$.

Finalmente, en relación con la actio que nos ocupa, establece un texto de Paulo en el libro 22 de los Comentarios al Edicto, contenido en Dig 9,1,4 ${ }^{38}$ que la actio de pauperie se extendió a los daños causados por otros animales, aun no cuadrúpedos, como actio utilis.

32 Dig. 9,1,1,7: Et generaliter haec actio locum habet, quoties contra naturam fera mota pauperiem dedit.

33 Sin embargo, los daños ocasionados por las fieras no dan lugar a la actio de pauperie, $c f$. el texto de Ulpiano en Dig. 9,1,1,10.

${ }_{34}$ Cf. Dig. 9,1,1,4 en la nota 29.

35 Sobre el particular, MARTínez SARRIón, Las raíces romanas de la responsabilidad por culpa, pp. 448-449.

36 Dig. 9,1,1,6: Sed et si instigatu alterius fera damnum dederit, cessabit haec actio.

37 Vid. Dig. $9,1,1,7$

38 Dig. 9,1,4. Haec actio utilis competit, et si non quadrupes, sed aliud animal pauperiem fecit. 
Por lo que se refiere a los perros que causaren daños, tienen en los textos romanos del Digesto un tratamiento diferente, según las situaciones; no se ha de aplicar la actio de pauperie, según vemos en Dig. 9,1,1,539 sino: tenebitur qui canem tenebat. En otro texto, en este caso de Paulo, perteneciente asimismo a los comentarios al Edicto, libro 22, recogido en Dig. 9,1,2,140, no se concede la actio de pauperie si el perro muerde a una persona en lugar cerrado donde ha ido a refugiarse; sí se aplica la citada acción si el perro estaba suelto y causa daños a la persona.

Asimismo, un texto de Gayo, relativo a los Comentarios al Edicto provincial $^{41}$ nos informa de la reclamación que procede al ejercitar la acción por los daños del cuadrúpedo y que se tengan en cuenta una serie de aspectos: sed impensarum in curationem factarum, et operarum amissarum, quasque amissurus quis esset inutilis factus.

\subsubsection{Edictum de feris}

Por otra parte, conforme a la regulación romana, el tener animales peligrosos en los sitios de mercado daba lugar, según el edictum de feris, a una acción que podían ejercer los que hubieran sido perjudicados en su cuerpo o en sus cosas contra quienes tuvieran dichos animales, y por la cual se pedía una indemnización por el doble del daño causado ${ }^{42}$. La citada disposición pertenecía al Edicto de los ediles curules ${ }^{43}$ que prohibía tener animales peligrosos sin atar y concedía una acción por el

39 Dig. 9,1,1,5, establece: sed est si canis, quum duceretur ab alio quo, asperitate sua evaserit, et alicui damnum dederit, si contineri, si contineri firmius ab alio poterit, vel si per eum locum induci non debuit, haec actio cessabit, et tenebitur, qui canem tenebat.

40 Dig. 9,1,2,1: si quis aliquem evitans, Magistratum forte, in taberna proxima se immisset, ibique a cane feroce laesus esset, non posse agi canis nomine quidam putant; at, si solatus fuisset, contra.

${ }^{41}$ El texto de Gayo en Dig. 9,1,3, establece lo siguiente: ex hac lege iam non dubitatur, etiam libersarum personarum nomine agi posse, forte si patremfamilias aut filiumfamilias vulneraverit quadrupes; silicet ut non deformitatis ratio habeatur, quum liberum corpus aestimationem non recipiat, sed impensarum in curationem factarum, et operarum amissarum, quasque amissurus quis esset inutulis factus.

42 Mommsen, Derecho penal romano, p. 515.

43 Aediles curules, magistratura creada en la época republicana, año 367 a. C., reservada en sus comienzos a los patricios y pronto hecha accesible a los plebeyos, encargada de la policía de la ciudad, vía pública y mercados, incendios, pesos y medidas, cuidado de los edificios públicos y organización de los juegos públicos. Gozaban de la jurisdicción civil en relación a las transacciones realizadas en los mercados de esclavos y animales y en relación a las materias en que tenían competencia, con facultad de imponer multas por las faltas cometidas contra sus prescripciones. Vid. GutiérRez-Alviz, Diccionario de derecho romano, p. 52. 
daño que aquéllos pudieran causar: de una pena de 200.000 sestercios si mataban a un hombre libre ${ }^{44}$, de la estimación (quanti bonum et aequum iudici videbitur) si lo herían, y del doble del daño en otros casos.

Asimismo, un texto del jurista Ulpiano contenido en Dig. 9,1,1,1045 se refiere a las fieras que por razón de su natural ferocidad causen daños después de huir, estableciéndose en este caso, según el texto del mencionado jurista que «no puede ser demandado el que fue su dueño, porque dejó de ser dueño».

\subsection{Sentencias de Paulo}

También en las Sentencias de Paulo se encuentra regulada esta materia relativa a los daños causados por animales. Así, concretamente en PS 1,15, bajo la rúbrica: si quadrupes damnum intulerit se establece ${ }^{46}$, en primer lugar, que la actio de pauperie fue extendida a los perros en virtud de una desconocida lex Pesolania ${ }^{47}$. En este primer tratamiento especial para el perro puede verse un residuo de la concepción primitiva de la responsabilidad de los animales, especialmente el perro ${ }^{48}$ (que no es un animal mutus). Esta concepción fue pronto superada por la jurisprudencia romana (cf. Dig. 9,1,1,3), pero reaparece en la Edad Media: un caso típico de atavismo jurídico ${ }^{49}$.

Por otra parte, el mismo texto de las Sentencias de Paulo libera de responsabilidad al dueño o al guarda del animal si el mismo es hostigado por un tercero y se expresa en los siguientes términos: ei, qui inritatu suo feram bestiam uel quamcumque aliam quadrupedem in se

${ }^{44}$ Con relación a la muerte dada a un hombre libre, el derecho honorario o de los magistrados dispuso que en caso de homicidio, no doloso, sino culposo, si éste hubiera sido causado por un animal fiero que indebidamente tuviese alguna persona, el autor del mismo debía ser condenado a pagar por vía de pena una indemnización de 2.000 sestercios, indemnización que subía a 5.000 sestercios si el homicidio hubiera provenido de haber tirado o arrojado alguna cosa que matara a la víctima. Cf. Mommsen, Derecho romano penal, p. 514.

45 Dig. 9,1,1,10: in bestiis autem propter naturalem feritatem haec actio locum non habet; et ideo si ursus fugit et sic nocuit, non potest quondam dominas conveniri, quia desinit dominus esse, ubi fera evasit; et ideo et si eum occidi, meum corpus est.

46 PS 1,15,1: si quadrupes pauperiem fecerit damnumue dederit quidue depasta sit, in dominum actio datur, ut aut damni aestimationem subeat aut quadrupedem dedat: quod etiam lege Pesolania de cane cauetur.

47 Lex Pesolania, se trata de una ley rogada de fecha dudosa, que extendió la responsabilidad noxal por daños producidos por los perros, cf. Gutiérrez-Alviz, Diccionario de Derecho romano, p. 414.

48 Vid. D’ORs, Derecho romano privado, (Pamplona, 1986), p. 429, n. 4.

49 Ibidem. 
proritauerit eaque damnum dederit, neque in eius dominum neque in custodiem actio datur ${ }^{50}$.

\section{La regulación en el derecho visigodo ${ }^{51}$ : la Lex Visigothorum ${ }^{52}$}

\subsection{Consideraciones previas}

Una vez analizada la regulación jurídica romana relativa a la responsabilidad de los daños causados por animales en las personas, nos centramos seguidamente en la legislación de los visigodos, concretamente en el texto legal conocido con el nombre de Lex Visigothorum. La citada ley dedica algunas disposiciones al tema que es objeto de nuestro estudio en los términos que iremos viendo en las siguientes líneas. Contiene la Lex una elevada dosis de derecho romano más o menos

50 Cf. PS $1,15,3$.

${ }^{51}$ El reino visigodo, antes de su establecimiento definitivo en Occidente, se constituyó en estrecha relación con el Imperio, al que desde antiguo venía prestando servicios militares de frontera bajo la fórmula del foedus (cf. RAFAEL GIBERT, «El reino visigodo y el particularismo español», en Cuadernos del Instituto Jurídico Español, 5. Estudios visigóticos, I (Roma-Madrid, 1956), p. 17 y las notas 6 y 7). El primer período del asentamiento de los visigodos en las Galias y en la parte noroeste de la Península, dominio que por el occidente llegó al parecer hasta Zaragoza, se inscribe en la estructuración del Imperio Romano, en la etapa anterior a la caída de Roma por los hérulos (cf. entre otros, ORLANDIS, J., Historia de España. La España visigótica (Madrid, 1977), pp. 59 y ss. GARCía GAllo, A., «Consideración crítica de los estudios sobre la legislación y la costumbre visigoda», en AHDE, (1974), pp. 424 y ss. A partir del año 476, con la entrada de Odoacro en Roma, la situación sufrió transformaciones profundas que se manifestaron de forma desigual en los distintos territorios sobre los que estaban asentados los visigodos. Durante esta época perdura la misma estructura territorial y política y al mismo tiempo los órganos de la administración romana continúan desarrollando las funciones de gobierno, con cierta intervención de los monarcas visigodos. Con Eurico, el primer monarca visigodo, y su hijo Alarico se da un paso más al ocupar éstos el lugar que antes había desempeñado el emperador, ejerciendo sus poderes y facultades. A partir de este momento es cuando podemos hablar propiamente de una legislación visigoda; entre otros, puede verse: ARANGIO RuIz, Historia del Derecho romano, 4. ${ }^{\mathrm{a}}$ ed.; trad. esp. (Madrid, 1989), pp. 448 y ss. García Moreno, L.A., Historia de la España Visigoda (Madrid, 1989), pp. 317 y ss. LALINDE ABADÍA, El derecho en la historia de la humanidad (Barcelona, 1982), pp. 38 y ss. Finalmente hemos de decir que son los visigodos uno de los pueblos germánicos más romanizados de los que se asientan en el antiguo territorio del Imperio Romano occidental. Entre los autores modernos no deja de reconocerse la profunda romanización de los reyes visigodos; sobre el particular, ver entre otros, D’Ors, «El Código de Eurico», en Cuadernos del Instituto Jurídico Español. Estudios Visigóticos, II (Roma-Madrid, 1960), 9.

$52 \mathrm{Cf}$. la nota 3. En relación con la Lex Visigathorum se utiliza la ed. de K. ZeUMER en Monumenta Germanine Historica (Leges), vol, 1 (Hannover-Leipzig, 1902). En adelante, LV. 
mezclado con otras adherencias de la época visigoda ${ }^{53}$. Se puede decir siguiendo a García y García ${ }^{54}$ que se da en la Península un derecho romano soterrado o latente, aunque en una dosis muy diversa según se tratara de las zonas peninsulares donde estaba en vigor o no el Liber Iudiciorum. Se estructura la citada ley en 12 libros y concretamente en el libro 8 trata, entre otras cosas, de los daños causados por animales.

Por lo que se refiere a nuestro tema de estudio, la ley de los visigodos distingue dos títulos de damnis: uno, en la LV ,8,3: de damnis arborum, ortorum et frugum quarumcumque y, el otro, en la LV 8,4: de damnis animalium vel diversorum rerum, concretamente este último bastante heterogéneo. Asimismo, otro texto legal, como es la Lex Baiuvariorum ${ }^{55}$ presenta algunos títulos relativos a los daños, así, concretamente la disposición contenida en LB 14, que lleva la rubrica: de vitiatis animalibus et eorum conpositone; además, otros dos títulos que hacen referencia a los animales de caza: en primer lugar, LB 20: de canibus et eorum conpositione y LB 21: de accipitribus; por otra parte, en relación con otra materia diferente, en LB 22: de pomeriis et eorum conpon(sitione). La base Euricia$\mathrm{na}^{56}$ de estas leyes es muy amplia y le permite a D`Ors ${ }^{57}$ establecer la división de esta materia en los títulos, pertenecientes al Código de Eurico ${ }^{58}$

53 García y García, A., «El derecho común en Castilla durante el s. XIII», en Glossae. Revista de Historia del Derecho Europeo, 5-6 (1993-94), pp. 55 y ss.

54 Ibidem, p. 55.

55 Se trata de la legislación bávara que suele datarse hacia la mitad del s. VIII y es tenida en cuenta por ZEUMER para la reconstrucción de la legislación de Eurico, ya que se considera que la ley bávara había tenido el Código de Eurico como modelo y que presentaba en ocasiones una versión del citado Código más auténtica que la procedente de las leges antiquae. Sobre el particular, UREÑa y SMENJAUd, La legislación gótico-hispana, pp. 243 y ss. ZEUMER, Historia de la legislación visigoda, pp. 28 y ss.

56 Se han transmitido elementos del Código de Eurico a través de la Lex Baiuvariorum, por medio de las antiquae contenidas en la Lex Visigothorum, además de los numerosos fragmentos contenidos en el palimpsesto parisino (Lat. 12161).

57 Vid. D’Ors, «El Código de Eurico», en Estudios visigóticos II (Roma-Madrid, 1960), p. 158.

${ }^{58}$ El Código de Eurico fue publicado según Zeumer, Historia de la legislación, 67, después del año 469, pero antes del 481, alrededor del año 475. En adelante CE. Un estudio de conjunto sobre el CE puede verse en D’Ors, A., «El Código de Eurico», Cuadernos del Instituto Jurídico español, 12 (Roma-Madrid, 1960). Establece el citado autor la fecha del CE en el 476 d.C. y considera que el Código de Eurico es propiamente un edicto y no un codex como pudo ser el Código Teodosiano, D’ORs, «El Código de Eurico», 3. Según el citado autor (que ha realizado una edición y palingenesia del texto euriciano), el Código o Edicto de Eurico, aunque posee vestigios o detalles de costumbres germánicas, está profundamente romanizado; en su redacción intervinieron buenos conocedores del Derecho romano - como León de Narbona-, pertenece a la cultura jurídica romana existente en el Sur de las Galias en la segunda mitad del s. v y es, en suma, un monumento de Derecho romano vulgar, ibidem, pp. 1-12. 
y que menciona a continuación con un carácter puramente conjetural: los daños en cultivos (XIX de damnis arborum $)^{59}$, los daños en los animales $(\mathrm{XX} \text { de vitiatis animalibus })^{60}$, los daños causados por los animales en las personas (XXI de vitiosis animalibus) ${ }^{61}$ y las perturbaciones en los caminos (XXII de iter agentibus) ${ }^{62}$.

\subsection{Disposiciones legales relativas a los daños causados por animales}

Nos referimos también aquí a la responsabilidad de los daños que los animales causan en las personas (o en otros animales), lo que presupone una especial naturaleza peligrosa, es decir, un vitium del animal poseído. Las disposiciones que tienen relación con esta materia se encuentran fundamentalmente en la LV 8,4: de damnis animalium vel diversorum rerum, como se ha dicho supra, menos una recogida en la LV 8,6, bajo la rúbrica: de apibus et earum damnis.

En primer lugar, en la disposición antiqua, contenida en la LV 8,4,1763, se ordena al poseedor de un animal peligroso el darle muerte, en caso contrario ha de responder del daño que ocasione como si lo hubiera causado él personalmente. Leovigildo completó esta disposición fijando la tasa de la conpositio debida según la edad de la persona muerta, según se establece en LV 8,4,16, que tiene la siguiente rúbrica: si vitiosum animal, cum aput dominum est, cuiuscumque etatis occidisse hominem videatur.

59 Conforme a la palingenesia del contenido del Código de Eurico que realiza D’ORS, dentro de este primer título sobre daños en los cultivos hay que distinguir, A) Daños causados por personas, B) Daños causados por animales, C) Daños en cercados de fincas, cf. D’ORS «El Código de Eurico», pp. 158 y ss.

${ }^{60}$ El contenido de este título se corresponde fundamentalmente con la primera parte (las antiquae 1 y 3-15) de la LV 8,4: de damnis animalium (vel diversorum rerum). En relación con las antiquae, pertenecientes a la Ley de los visigodos, véase la nota 3.

${ }^{61}$ Se trata de la responsabilidad de los daños que los animales causan en las personas o en otros animales.

62 La conexión de este título con los anteriores viene dada ya en las mismas fuentes romanas (PS 1,14: de vía publica y en PS 1,15: si cuadrupes damnum intulerit). Tienen relación con el contenido del citado título las disposiciones antiquae de LV 8,4, 22-30 y asimismo, las antiquae de la LV 8,3, 3; 4 y 9.

${ }^{63}$ LV 8,4,17, antiqua, establece: si animal vitiosum quis a se abiciat vel non abiectum retineat. Si quis bobem aut alium animal nocivum vel vitiosum habuerit, eum occidere non moretur vel a se proicere; ita ut vicinis omnibus notum faciat, quia eum a se proiecit. Quod si eum non occiderit, sed reservaverit, quidquid damni fecerit, ille conponat, qui eum aput se reservare cognoscitur. Según D’Ors «El Código de Eurico», 169, Zeumer y Ureña consideran esta ley como no euriciana. 
Por lo que respecta a las disposiciones contenidas en el Fuero Juzgo, concretamente en FJ 8,4,1764, que lleva la rúbrica: si algun omne non quiere quitar de sí el animalia que es brava, establece también que el poseedor del animal pague el doble de los daños que causare. Asimismo, en el FJ 8,4,16 $6^{65}$ si el animalia que es brava mata algun omne, se establece aquí también el criterio de composiciones en función de la edad de la persona que mata el animal.

Por otra parte, hemos de decir además, en relación con los daños causados por cuadrúpedos que en la LV 8,4,12, antiqua $^{66}$, se establece el régimen de noxalidad, esto es, el dueño del animal puede o bien entregar el animal y quedar así libre de responsabilidad o pagar la indemnización correspondiente por los daños causados, conforme a lo que se regula en el derecho romano en los términos que hemos visto supra. De la misma forma se expresa la disposición contenida en FJ 8,4,1267, cuando tienen lugar los daños causados por algún animal.

${ }^{64} \mathrm{FJ} 8,4,17$. Si algun omne ha buey bravo, ó otra animalia, mátelo luego, ó quitelo de sí, é fágalo saber á los vecinos que lo quitó de si: é si lo non quisiere matar, ni lo quitar de si, mas si lo quisier tener, quanto danno fiziere despues péchelo en duplo.

65 FJ 8,4,16: si el animalia que es brava mata algun omne. Si algun omne ha buey bravo, ó toro, ó baca, ó otra animalia, mátele luego ante que faga mal: é si lo sabe por los vecinos quel dixeron que es tal, é despues lo toviere ó lo governare, é no lo quisier luego matar, é despues matar algun omne, o firiere, faga ende emienda al sennor, cuemo manda la ley del omecillo de los omnes, é de las mujeres, de los ninnos, é de los siervos, é de las siervas, assi que si aquela animalia matar omne ondrado, peche el sennor por el omecilio de los omnes D. sueldos: por omne libre de menor guisa, que haya XX annos, peche CCC. Sueldos, é por omne franqueado, peche la meatad desta emienda. E esta emienda misma mandamos facer por omne que mata fasta L. annos. E por omne de LX É $V$. annos adelantre peche CL. Sueldos. E si la animalia matar omne de XV. Annos, peche el sennor por el omecillio C. é L. sueldos: é por omne de XIII annos peche C. é X. Sueldos, é por omne de X. Annos peche C. sueldos, é por omne que haya IX Annos, ó VIII, ó VII, peche XC sueldos: por omne que aya VI. Annos, ó V, ó IIII, peche LXXX. Sueldos; é por omne que aya III. é II. annos peche LXX sueldos. E si matar mugier el animalia de algun omne, si es la mugier de XV annos fasta XL. Peche el sennor del animulia por el omecillio C. é L. sueldos. E si matar mugier que aya XL. Annos fosta LX. Peche el sennor del animalia CC. Sueldos por el omecillio: é por mugier que a de LX. Annos arriba peche C. sueldos. E si matarmugier de XV annos en ayuso peche la meatad de la emienda que es dicha de suso de los ninnos de XV. Annos en ayuso, segúnd la edad de cada uno. E si la animulia matare siervo aieno, el sennor del animalia peche otros talas dos siervos al sennor del siervo.

${ }^{66} \mathrm{LV} 8,4,12$, antiqua. Si animal cuicumque faciat quodcumque damnosum. Si cuiuscumque quadrupes aliquid fecerit fortasse damnosum, in domini potestate consistat, utrum quadrupem noxium tradat, an ei, qui damnum pertulit vel aliquid excepit adversi, iuxta indicis extimationem conponat.

67 FJ 8,4,12, que lleva la rúbrica: si bestia ó animalia dañosa de quien quier face danno. 
Otro aspecto a tener en cuenta en la misma sede de la Lex Visigothorum es el contenido en la LV 8,4,18, antiqua ${ }^{68}$; la citada antiqua, exime aquí de responsabilidad al propietario cuando el animal causante de los daños fuese provocado, lo que sigue siendo conforme al derecho romano de la actio de pauperie ${ }^{69}$. Hay que destacar asimismo que la citada disposición menciona expresamente al perro, ya que a este animal se había extendido el mismo régimen desde la lex Pesolania, según se indica en las PS $1,15,1^{70}$. Sin embargo, en la época de Leovigildo vamos a ver cómo el perro vuelve a separarse de los otros animales «mudos», lo que pone en evidencia el regreso de la idea primitiva de que el perro delinque él ${ }^{71}$.

En FJ 8.4,1872, que lleva la rúbrica: si algun omne faz algun espanto con mano ó con otra cosa, a la animalia, e lo mata, exime asimismo de responsabilidad al dueño del animal.

Precisamente, según D’Ors ${ }^{73}$, las antiquae contenidas en LV 8,4,1974 y $20^{75}$ deben atribuirse a Leovigildo. En la primera disposición citada el dueño no responde de los daños causados por la mordedura de un perro

${ }^{68}$ LV 8,4,18, antiqua. Sue habendum culpe, si irritatum animal noceat irritantem. Si quis vitiosum bobem aut canem vel alium animal contra se in ira concitaverit, quidquid passus fuerit, culpe eius, qui hoc pertulerit, oportet adscribi.

${ }^{69}$ Cesa la aplicación de la actio de pauperie en el supuesto al que se refiere el texto en Dig. 9,1,6: sed et si instigatu alterius fera damnum dederit, cessabit haec actio. Asimismo, se recoge esa circunstancia en el texto contenido en PS 1,15,3: ei, qui inritatu suo feram bestiam uel quamcumque aliam quadrupedem in se proritauerit eaque damnum dederit, neque in eius dominum neque in custodem actio datur.

70 Cf. la nota 46.

71 Esto demuestra hasta qué punto revivía la antigua idea, que el derecho romano superó, de que el mismo animal es el delincuente: el perro parece más responsable que los otros animales, porque parece que se da más cuenta. Quizá, antes de la citada lex Pesolania, también el perro estaba sometido a un régimen de mayor responsabilidad que los demás animales, vid. D'ORs, Miscelánea en AHDE, 17, (1946), p. 924.

72 FJ 8,4,18: si algun omne faz algun espanto con mano ó con otra cosa á la animalia, é lo mata. Si algun omne enriza buey, ó can ó otra animalia contra si, quanto danno le fiziere el animalia, tórnese á su culpa.

73 D’Ors, «El Código de Eurico», p. 169.

${ }^{74} \mathrm{LV}$ 8,4,19, antiqua. Si iuste an iniuste concitatus canis quempiam debilitasse vel occidisse probetur. Si aliquem canis momorderit alicuius, et de morsum illius aliquis debilitatus probetur aut mortuus, domino canis nihil calumnie moveatur; si tamen eum canem, ut morderet, non nritasse cognoscitur. Quod si canem suum, ut furem aut quemcumque criminosum conprehenderet, inritavit, et ita momorderit fugientem, si de morso ipso fuerit debilitatus aut mortuus, nihil ex eo causationis exsistat. Nam si eum ad innocentem forsitaminiuriandum incitavit, tamquam si ipse vulnus intulerit, iuxta legem conponere non moretur.

${ }^{75}$ LV 8,4,20, que lleva la rúbrica: de cane damnoso. 
a una persona; ahora bien, ha de responder si ha incitado al perro contra una persona no sospechosa, según establece la ley: tamquam si ipse vulnus intulerit, iuxta legem conponere.

Podemos referirnos asimismo al FJ 8,4,1976 que tiene como rúbrica: si el can que es enrizado mata algun omne, ó muerde y que se manifiesta en los mismo términos que la citada ley de los visigodos, es decir, en este caso no responde el dueño del perro; solamente responde de los daños causados por el mismo, si el dueño lo enrizar que muerda omne que non es malfechor.

Antes de dar por concluido el presente apartado, aludimos brevemente a determinados daños que puedan causar ciertos animales a otros animales. Así, en primer lugar, los daños que ocasione el perro: la ley contenida en LV 8,4,20, antiqua ${ }^{77}$, destaca muy claramente la idea de que el perro que daña el ganado ajeno debe ser muerto o por el mismo dueño o por el damnificado; si no acepta la citada responsabilidad, contrae la obligación - y al duplum - respecto a los daños futuros que el perro cause en el rebaño del propietario damnificado anteriormente.

Por otra parte, en relación con la disposición en el FJ 8,4,2078, el contenido de la misma aparece en términos similares a los de la ley de los visigodos, como se acaba de ver.

Finalmente, por lo que respecta a los daños que puedan causar las abejas, se refiere a los mismos la ley de los visigodos en LV 8,679, que

76 FJ 8,4,19. Si el can que es enrizado mata algun omne, ó muerde. Si algun can muerde algun omne, é de la mordedura muere el omne, ó enflaquece, el sennor del can, non debe aver nenguna calonna, si el sennor non enrizó el can que lo mordiesse. $E$ si el sennor del can enriza el can que prenda ladron ó otro malfechor, é de la mordedura muere ó enflaquece el ladron ó el malfechor, el sennor del can non debe aver nenguna calonna. Mas si lo enrizar que muerda omne que non es malfechor, quanto danno ficiere el can todo lo debe pechar el sennor, segund la ley, cuemo si lo él mismo ficiese.

77 LV 8,4,20, antiqua. De cane damnoso. Si cuiuslibet canis damnosus fuerit, ut devastet berbices aut alia pecora forte evertere ceperit, et deprehensus fuerit, ipse dominus canis, ubi ex hoc fuerit conmonitus, eum illi tradat, cui damnum constat fuisse intalum, ut eum occidat. Quod si eum occidere noluerit vel illi tradere, cui damnum primitus constat fuisse inlatum, quidquid postmodum canis damni admiserit, dominus canis duplam conpositionem reddere non moretur.

78 FJ 8,4,20. Del can que mata ganado. Todo omne que ha can que mata ovejas, ó otro ganado, el sennor del can debe dar el can al que fizo el danno, é lo mate luego: é si lo non quisier dar á aquel á qui fico el danno primeramientre, quanto mas danno fiziere despues el can, todo lo debe pechar en duplo.

79 El título correspondiente a LV 8,6, consta de tres leyes: LV 8,6,1: de inventis apibus defendendis; LV 8,6,2: si damnum faciant apes y LV 8,6,3: De furatis apibus. 
lleva la rúbrica: de apibus et earum damnis. Nos interesa fundamentalmente la disposición contenida en la LV 8,6,2, la cual bajo el título: si damnum faciant apes, se refiere a la muerte o debilitación de un cuadrúpedo por obra de las abejas, habiendo sido ya requerido el propietario de las colmenas para trasladarlas a otro sitio; con lo cual la ley parece prever una especial situación de peligrosidad.

Del mismo modo, en FJ 8,6,2 se refiere al danno que fazen las abeias.

\section{Regulación de los daños causados por animales en determinados fueros $^{80}$ de la Alta Edad Media española}

Nos vamos a referir, concretamente, a algunos fueros altomedievales que contienen disposiciones relativas a los daños que puedan causar los animales y a la responsabilidad del propietario de los mis$\operatorname{mos}^{81}$; en primer lugar, hemos de decir que ideas de venganza hacia los animales y de atribución de una responsabilidad por sus propios hechos se contienen en textos aragoneses y navarros que figuran entre aquellos de la Alta Edad Media que acusan un fondo más arcaico. Una compilación privada de Derecho aragonés se refiere a los detalles de la venganza ejecutada contra el «cane que momorderit ad hominem» ${ }^{82}$. Por otra parte, el Fuero General de Navarra habla de que si un animal da muerte a otro, "la bestia que mata es homiziera desta bestia muerta» ${ }^{83}$.

80 Ya sabemos que la expresión «fuero» es una denominación genérica y de sentido múltiple. Entre las distintas acepciones que a este término pueden darse (privilegios, derecho de un individuo, conjunto de derechos en general, documentos que los contienen, ordenamiento jurídico no formulado, ley) nos interesa ahora solamente el siguiente concepto de Fuero: conjunto de normas jurídicas que regulan la vida local y las cargas y derechos de los vecinos y moradores, recogido en una redacción o texto único que es dado o recibe la confirmación (carta de confirmación) del rey o del señor, vid. PÉREZ-PRENDES, J.M., Curso de historia del Derecho español (Madrid, 1978), pp. 419-20.

81 Dedica un apartado a la responsabilidad del propietario por los daños que causaran sus animales y cosas, el excelente trabajo de OrLANDIS, José, «Sobre el concepto del delito en el Derecho de la Alta Edad Media», en AHDE, 16 (1945), pp. 112 y ss. Al mencionado trabajo le siguió otro del mismo autor, «Las consecuencias del delito en el Derecho de la Alta Edad Media», en AHDE, 18 (1947), pp. 61 y ss.

${ }^{82}$ Compilación privada de Derecho aragonés, 10, AHDE, I.

${ }^{83}$ Fuero General de Navarra, 5,4,14, bajo la rúbrica: de bestia que mata á otra, establece: si una bestia á otra matare, la bestia que mata es homiziera desta bestia muerta. Se ha consultado la edición del Fuero dirigida y confrontada con el original, que existe en el archivo de Comptos, por don Pablo IlarRegui y don Segundo LAPUERTA (Pamplona, 1869). 
Mas el criterio ordinario de nuestras fuentes medievales era establecer una responsabilidad que recaía sobre el dueño del animal. No le alcanzaban las consecuencias de índole puramente penal que se derivarían de la acción si la hubiera cometido personalmente ${ }^{84}$. Además fue un sistema muy difundido el de conceder al propietario un derecho de opción, o bien la entrega del animal causante del daño o el pago de la multa que como sanción pecuniaria se le impusiere ${ }^{85}$. Otros textos, en cambio, imponen con carácter obligatorio, la entrega del animal ${ }^{86}$. Además, la peligrosidad del animal, reconocida y declarada con anterioridad, podía originar la agravación de la pena económica que se imponía al dueño ${ }^{87}$.

\section{Recepción del Derecho romano}

\subsection{Consideraciones generales acerca del ius commune en Europa}

Conscientes del riesgo e imprecisión que todo lo general comporta, por vía de síntesis, podemos decir lo siguiente. Como es sabido, en la historia del derecho es cada vez más frecuente la configuración de un período con caracteres peculiares comprendido entre los siglos XIII al XVIII, cuya coherencia consiste en la vigencia del derecho común, esto es, de un derecho elaborado en las ciudades europeas a partir del siglo XII sobre la base del

${ }^{84}$ Sobre el particular, cf. ORLANDIS, J., «Sobre el concepto del delito...», p. 148.

85 Podemos referirnos a algunos textos legales, cf. MuÑoz RoMERo, Tomás, Colección de fueros municipales y Cartas Pueblas de los reinos de Castilla, León, Corona de Aragón y Navarra, coordinada y anotada por el citado autor, (Madrid, 1847), reedición (Madrid, 1970), p. 442, Fuero de Medinaceli: «... de can qui ombre matare, si el can podiere dar, non peche por ende nada, si el can non diere peche al rey omicidio plano, cuya vestia, cual quisiere buey, o vaca, ombre matare, si el danador diere, non peche nada; si nol diere peche LX sueldos...». Fuero de Soria, p. 509: Si el ganado o bestia de alguno, como thoro o vacca o otro ganado o cauallo o otra bestia, matare a alguno, quier sea suelto quier non, el sennor de la bestia o del ganado de al dannador o peche el precio que ualier, cf. Fueros castellanos. De Soria y Alcalá de Henares. Edición y estudio de Galo Sánchez (Madrid, 1919). En parecidos términos otros Fueros de la Colección citada supra se refieren al derecho de opción del propietario.

86 Cf. por ejemplo, el Fuero de Daroca del año 1142, recogido en la Colección citada en la nota 86 establece, entre otras cosas, en la p. 539: «... si bestia alicuius, vel canis, vel quodlibet animal occiderit aliquem, dominus eius non pectet homicidium, nec aliam calumniam, sed perdat bestiam, si inquisitum fuerit dum illa habuerit...»

87 Cf. Ledesma, 229: De can que omne mordir. Can que omne mordir, peche su duenno XXX soldos; e se su duenno dixier: non quiero pechar por ella, meta el can en mano del rancuroso bien preso, e faga delle su voluntade. E si el can fuer testado en conceyo, e despues omne mordir, peche su dueno LX soldos... 
derecho romano justinianeo ${ }^{88}$. Es cierto que la penetración del derecho común en los distintos territorios (dentro y fuera de la Península Ibérica), no fue pacífica, sino que tuvo que vencer resistencias más o menos acusadas. La recepción del derecho romano-canónico significó en todos los casos la lucha entre un derecho nuevo y el derecho viejo o tradicional de cada país ${ }^{89}$. No obstante, a pesar de la resistencia a la que se ha aludido hay que decir que durante siglos los países de Europa occidental y central tuvieron un derecho común, esto es, un ius commune y una ciencia jurídica común. Este derecho común era el derecho romano-canónico y estuvo vigente desde fines de la Edad Media hasta la época de la Revolución Francesa en los países centrales y occidentales del continente europeo ${ }^{90}$.

En el ius commune se integra también el derecho canónico, como se acaba de hacer mención, de manera que, según Calasso ${ }^{91}$, puede decirse que el ius commune es la unión indisoluble y típica de las dos leyes universales canónica y civil, constituyendo así unum ius, ya que

88 Sobre el particular; GARCÍA y GARCíA, A., «El derecho común en Castilla durante el siglo XIII», Glossae. Revista de historia del derecho europeo, pp. 5-6 (Universidad de Murcia, 1993-94), p. 46; al referirse el autor al contenido y formación del derecho común comienza diciendo que no es fácil describirlo, pero es todavía más difícil definirlo. Y continúa diciendo, el autor citado, que este enunciado (alude al derecho común) se refiere al ordenamiento que emerge de los textos de las colecciones legales justinianeas redescubiertas en el s. XII, después de seis siglos de eclipse más o menos total o parcial, a los que pronto se sumaron los principales textos canónicos del primer milenio del cristianismo compilados por Graciano hacia 1141-50 y vigorosamente incrementados por las decretales o cartas pontificias y por los concilios generales de la Iglesia desde 1123 hasta 1311-12. Idem, «La penetración del derecho clásico medieval en España», AHDE, (1966), pp. 575 y ss. Font Ríus, «La recepción del derecho romano en la Península Ibérica durante la Edad Media», en Recueil de memoir et travaux, 1967, n. ${ }^{\circ}$ 6, pp. 86 y ss. También, cf. PÉREZ MARTín, A., «La obra legislativa alfonsina y puesto que en ella ocupan las Siete Partidas», Glossae. Revista de historia del derecho europeo, 3 (1992), pp. 10 y ss. TomÁs Y VALIENTE, F., Manual de historia del derecho español (Madrid, 1981), p. 167.

89 Entre otros, puede verse, FonT Ríus, «La recepción del derecho romano en la Península Ibérica durante la Edad Media», pp. 92 y ss., se refiere precisamente a las resistencias a la penetración del derecho romano en el ámbito de la Península Ibérica. Tomás Y VALIENTE, F., Manual de historia del derecho español, p. 201. El citado autor dice también a continuación que la mayor o menor intensidad y rapidez de la penetración del derecho nuevo, del derecho de los juristas, estaba condicionada por el distinto grado de arraigo, homogeneidad y calidad de los diferentes derechos tradicionales, ibidem, p. 201.

90 Entre otros, CoIng, H., Derecho privado europeo (Madrid, 1996), p. 31. También recientemente, CALONGE, «La recepción del derecho romano», en Actas I Congreso Iberoamericano de Derecho Romano (Granada, 1995), p. 11: hay que tener en cuenta que desde la fundación de las Universidades (en torno al siglo XII) y hasta el siglo XVIII, en toda Europa, no se estudia otro Derecho que el común medieval contenido en los dos Corpus Iuris.

91 Calasso, F., Introduzione al Diritto Comune (Milano, 1970), p. 108. La traducción es nuestra. 
la coexistencia en un mismo ordenamiento de dos derechos comunes es conceptualmente inadmisible.

Dos razones señalan los autores, entre ellos, Coing 92 , por las cuales el derecho romano-canónico se convirtió en derecho común: 1) La posición de poder de la Iglesia latina en la Edad Media y 2) El acontecimiento cultural que es designado usualmente con la expresión de «Recepción». La recepción, como es sabido, tiene su origen en el redescubrimento científico del derecho romano, concretamente del derecho justinianeo, por los juristas italianos, en particular en los siglos XI y XII en Bolonia y cuya compilación legislativa se conoce, a partir de la Edad Media con la expresión Corpus Iuris Civilis. Los glosadores encuentran en el derecho justinianeo un sistema jurídico completo y desde finales del siglo XI y en el siglo XII se convierte en Bolonia el citado derecho en la base de la enseñanza jurídica ${ }^{93}$.

Hay que tener en cuenta además que, así como los legistas tenían a su disposición la legislación de Justiniano, los canonistas no podían recurrir a una colección oficial de las fuentes jurídicas eclesiásticas. Tenemos, por otra parte, que el desarrollo posterior del derecho canónico se operó por la actividad legislativa y judicial de los papas medievales que fue recogida en diversas colecciones oficiales. Con ello se había formado el Ius utrumque de la Edad Media. Y así resulta que desde la fundación de las Universidades (en torno al s. XII) y hasta el s. XVIII, en toda Europa no se estudia otro Derecho que el común medieval contenido en los dos Corpus Iuris. De este modo, puede decirse, según Grossi ${ }^{94}$ que el derecho medieval no es derecho español, italiano y francés sumados conjuntamente, sino un Derecho auténticamente europeo, que porta en sí muchas manifestaciones autónomas pero al que tales autonomías jamás le hacen perder su calidad de tejido esencialmente supranacional.

92 CoIng, H., Derecho privado europeo, 31. La recepción, según el citado autor, es, en primer lugar, un acontecimiento de la historia de la educación, ibidem, p. 33.

93 Los glosadores encuentran en el derecho justinianeo un sistema jurídico completo, estructurado científicamente hasta un cierto grado, que satisfacía al deseo del tiempo por un fundamento racional, sobre el particular, entre otros, cf. CoING, H., Derecho privado europeo, p. 34.

94 Grossi, El orden jurídico medieval. Prólogo a la edición en castellano de Tomás Y VAliEnte, F., (Madrid, 1996), p. 14. Más adelante sigue diciendo el citado autor que ninguna civilización jurídica ha conocido, en efecto, un tejido unitario tan auténticamente europeo como la medieval, p. 29. Tiene razón el Profesor Fuenteseca cuando asegura que el Derecho romano tiene un puesto importante en la formación de los juristas de la nueva Europa, ya que constituye un factor decisivo en la Historia del Derecho europeo, cf. FUENTESECA, «Observaciones sobre el futuro del Derecho romano en España», Estudios en homenaje al Profesor Hernández-Tejero (Madrid, 1992), pp. 205 y ss. 
En España concretamente, el derecho romano ha tenido en su desarrollo histórico una importancia fundamental por haber constituido uno de los elementos básicos del derecho peninsular en sus diversas manifestaciones ${ }^{95}$. En la época bajomedieval, con Alfonso X el Sabio, se produce, al igual que en Europa, la recepción del derecho romano a través del derecho común. En líneas generales, se pueden distinguir dos épocas en cuanto al romanismo en algunos territorios hispánicos ${ }^{96}$ : en primer lugar, la época del derecho romano indígena, época anterior a la recepción del derecho romano común y que corre desde el s. VI hasta el s. XII (fines). En segundo lugar, la época de la recepción y del desarrollo del derecho común, que abarca los siglos siguientes, hasta fines del s. XVIII, en el cual el ciclo de la penetración e influencia del derecho romano puede considerarse terminado.

Precisamente España contaba con una tradición visigótica de derecho romano vulgar que perduró en diferente medida según las condiciones de cada territorio tras la ocupación musulmana ${ }^{97}$. Posteriormente cuando tiene lugar la penetración del derecho justinianeo en España, podemos destacar siguiendo a Font Ríus ${ }^{98}$ una serie de factores que influyen en la misma: a) Las Universidades y la formación del estamento letrado. La creación y desarrollo de estas Universidades hispanas, sigue diciendo el autor, con sus bien organizadas facultades jurídicas y sus esclarecidos maestros constituyó un nuevo cauce de difusión del derecho común y de formación autóctona de juristas; b) Libros de derecho, textos legales justinianeos, summae y

95 Véase Larraona y Tabera, A., «El Derecho justinianeo en España», en Atti del Congresso Internazionale di Diritto Romano (Bologna e Roma, 1933), p. 85.

96 Ibidem, pp. 87 y ss.

97 FERNÁNDEZ BARREIRO, A., La tradición romanística en la cultura jurídica europea (Madrid, 1992), p. 42. Véase, asimismo, LARRAONA Y TABERA, A., «El derecho justinianeo en España», p. 100: el romanismo vivió en España en aquel oscuro período que va de la conquista Arabe (711) hasta el fin del s. XII por medio de la Lex Visigothorum, que en buena parte lo contenía; en relación con la citada ley, cf. la nota 3. El Liber, que había sido privadamente vertido al gallego, se tradujo al castellano oficialmente en fecha no conocida pero quizá todavía en el reinado de Fernando III con el nombre de Fuero Juzgo, denominación que desde entonces sustituirá a la latina. También puede decirse que la general vigencia del Liber supuso como una facilidad inicial para que el nuevo derecho fuese entendido y admitido en aquellos territorios donde estuvo vigente el texto legal citado, cf. ToMÁs Y VAliente, F., Manual, p. 203. También, Wesenberg y Wesner, Historia del derecho privado moderno en Alemania y en Europa, trad. al español por Javier de Los Mozos (Valladolid, 1998), dedica un capítulo del libro al derecho romano en España, pp. 122 y ss.

98 Font Ríus, «La recepción del Derecho romano en la Península Ibérica durante la Edad Media», en Recueil de memoir et travaux, pp. 87 y ss. García y García. A., Derecho común en España. Los juristas y sus obras (Murcia, 1991), presenta el autor una serie de juristas y sus escritos sobre el ius commune medieval en España. 
comentarios a los mismos de los glosadores y postglosadores, como instrumento de penetración y aplicación práctica del nuevo ius commune ${ }^{99}$.

Por lo que respecta a nuestro tema de estudio, destacamos en este lugar las Siete Partidas como uno de los textos legales más notables de la historia del derecho europeo, tanto por su origen, como por su contenido e influjo y son un gran exponente de la recepción del ius commune en la España medieval ${ }^{100}$. Por otra parte, hay que tener en cuenta que, al mismo tiempo que los derechos extranjeros penetran con impulso irresistible en la monarquía castellana amenazando sumergir por completo los viejos derechos territoriales, los redactores de los textos legales de los citados derechos nos dan a conocer el derecho típicamente castellano. De esta manera, cuando triunfaba la doctrina romano canónica, que casi ahoga el papel de la costumbre como fuente del derecho, ésta es exaltada en tales textos $^{101}$. Concretamente, las redacciones del derecho territorial castellano que se conservan son agrupadas en dos series: breves y extensas. Estas últimas aspiran a recoger el antiguo derecho territorial castellano en su conjunto, el Libro de los Fueros de Castilla y el Fuero Viejo corresponden a esta serie. Las redacciones breves recogen sólo determinados aspectos que interesan fundamentalmente a sus redactores; las Devysas, los falsos Orde-

99 Establece CALONGE, «La recepción del derecho romano», pp. 11 y ss. que para el estudio del Derecho romano a partir del s. XII será imprescindible seguir las vías de penetración del mismo, entre las que cabe destacar las siguientes: un primer cauce de penetración en España se da a través de colecciones como los Usatges de Cataluña, las consuetudines Ilerdenses, las Costums de Valencia y Tortosa, los fueros de Aragón y, sobre todo, las Partidas. Otro camino de penetración lo encontraremos en la práctica notarial, cuyos documentos conocemos fundamentalmente gracias a Font Ríus y a García y García. Debe rastrearse, asimismo, la vigencia del derecho romano a través de los estudiosos que acuden a las Universidades, principalmente a la de Bolonia. Al lado de los escolares que van hay también que tener en cuenta a los maestros extranjeros que vienen a enseñar a centros españoles. Otra vía de acceso al conocimiento y utilización del derecho romano en los reinos ibéricos son los libros jurídicos que son introducidos en España por los escolares.

100 A mediados del s. XIII se manifestaba la oposición de forma profunda y violenta contra los nuevos derechos en el reino de Castilla, donde Alfonso X se veía obligado, hacia 1270, a suspender la vigencia de sus códigos romanistas y a confirmar a nobles y ciudades sus antiguos fueros y costumbres, ante el espectáculo de un levantamiento general, derivante hacia una lucha civil; véase García Gallo, Manual de Historia del Derecho Español, 1. ${ }^{\mathrm{a}}$ ed. (Madrid, 1964), p. 390. El transcurso del tiempo favoreció la lenta y progresiva infiltración de los nuevos derechos en la práctica de los tribunales, e incluso en la legislación oficial de los diferentes reinos; pero la aversión popular hacia los juristas — jueces, abogados, gente de curia—, por su invocación inmoderada de autores romanistas y canonistas en los tribunales, y el empleo de un sistema procesal complicado a los ojos del vulgo, se mantenía viva todavía en pleno siglo XV, vid. FONT Ríus, «La recepción del derecho romano en la Península Ibérica durante la Edad Media», p. 93.

101 Cf. GALO SÁNCHEZ, «Para la historia de la redacción del antiguo derecho territorial castellano», AHDE, 6 (1929), p. 267. 
namientos de Nájera, el Fuero de los fijosdalgo, el Fuero antiguo de Castilla pertenecen a la serie de redacciones breves ${ }^{102}$. El estudio comparado del Fuero Viejo y del Libro de los Fueros de Castilla demuestra la existencia de una serie de disposiciones comunes entre ambos fueros, según el trabajo de Galo Sánchez ${ }^{103}$. Pero, por otra parte, sigue diciendo el autor citado, las diferencias de redacción en los capítulos de ambos textos legales, hacen pensar que ni el Fuero Viejo ${ }^{104}$ ha influido en el Libro de los Fueros de Castilla $^{105}$ ni éste en el Fuero Viejo. La coincidencia de ambos textos es completa en ciertos casos, en otros casos, hay disposiciones que faltan en el Fuero Viejo y están en el Libro y en otros casos al revés ${ }^{106}$.

\section{La regulación en el Fuero Real ${ }^{107}$}

A Alfonso X el Sabio se le atribuyen, con mayor o menor grado de certidumbre, tres obras fundamentales: el Fuero Real, el Espéculo ${ }^{108}$ y

102 Idem, p. 269.

103 Idem, pp. 297-298.

104 A mediados del s. XIV un jurista anónimo lleva a cabo la redacción sistemática de un texto llamado Fuero Viejo. Consta de cinco libros relativos a derecho público, penal, civil, organización judicial y procedimiento.

105 Contiene la más antigua redacción que se conserva del Derecho territorial castellano en su conjunto. No está fechado; pero en vista de ciertas peculiaridades del texto, se puede suponer que se redactó en Burgos en la segunda mitad del siglo XIII, sobre el particular, Galo Sánchez, Curso de Historia del Derecho. Introducción y fuentes. Décima edición revisada. (Valladolid, 1982), pp. 73-74.

106 Concretamente el citado Fuero Viejo de Castilla en el Libro 2, Título 5, dedica una rúbrica: De los daños, que se ficieren en Castiella. La ley 3 del citado título tiene, en primer lugar, relación con los daños (muerte, lesiones) que una persona causare a un perro y la indemnización correspondiente que hay que pagar según los casos. A continuación la mencionada ley establece: «... E si algund can, que está atado de dia por mandado de suo dueño, si algund daño ficier de dia, suo señor develo pechar, o dar el dañador; e si lo ficier de noche, non peche nada; e si demandare algund daño, que fiço de noche, el dueño debe responder como por bestia muda

107 Alfonso X elaboró y concedió una importante y sistemática obra que aunque recibió muy diversas denominaciones es, en general, conocida como Fuero Real. Está muy influido por el Liber ya que fue utilizado por los redactores del Fuero Real como modelo para muchos de sus preceptos. También hay claras influencias de las Decretales del papa Gregorio IX, véase, Tomás y Valiente, Manual, 164. Sobre este texto legal, puede verse asimismo, entre otros, PÉRez MARTín, A., «El Fuero Real y Murcia», AHDE, 54 (1984), pp. 55-96. Del mismo autor, «La obra legislativa alfonsina y puesto que en ella ocupan las Siete Partidas», pp. 19 y ss. En relación con los Códigos Antiguos de España se ha utilizado la edición de Martínez Alcubilla (Madrid, 1885).

108 El Espéculo es una obra incompleta, consta de cinco libros y se redactó probablemente entre 1255 y 1260 . Recibe este nombre porque en su prólogo se dice de ella que es 
las Partidas y en los tres textos legales ${ }^{109}$ se advierte una notoria influencia del derecho romano canónico.

En primer lugar, por lo que respecta al Fuero Real redactado en 1255, se establece en el prólogo que fue dado con consejo de los sabidores del derecho, para remediar la falta de fueros ya que en la mayor parte de sus reinos se juzgaba por fazañas e por albedríos departidos de los omes. Consta el texto legal de cuatro libros que tratan de materia política, religiosa, procedimiento civil y penal. Por lo que respecta al tema de nuestro estudio, esto es, la responsabilidad de los daños causados por animales, se regula en el citado texto legal en el Libro 4, Título 4, que lleva la siguiente rúbrica: de las fuerzas y de los daños.

Concretamente, es en la ley 20110: como debe pagar el daño el que diere causa a él, donde se refiere, en primer lugar, a la obligación de responder el causante de los daños causados, aludiendo a continuación a dos supuestos: 1) los daños que pueda causar algún animal manso (buey, ó can, ó otra bestia cualquier), a una persona, a un animal o en cosas; en este supuesto el dueño responderá de los daños: bien pagando la indemnización correspondiente, o bien entregando el dañador que lo fizo. 2) si fuera bestia brava (leon, ó oso, ó lobo, ó otra bestia semejable), ha de pagar el dueño la indemnización correspondiente si no tomó las precauciones pertinentes en relación con los citados animales; por el contrario, si a pesar de la diligencia debida los animales causaren daños, se le exige solamente al dueño la entrega del causante a quien sufrió el daño.

«espejo» del Derecho. Como fuentes del Espéculo, en líneas generales, se pueden señalar las mismas del Fuero Real y de las Partidas teniendo en cuenta que se asemeja a veces más a las de aquél que a las de éstas. Pérez Martín, A., «La obra legislativa alfonsina y puesto que en ella ocupan las Siete Partidas», Glossae. Revista de historia del derecho europeo, 3 (1992), p. 29. También puede verse, García GaLlo, «El Libro de las Leyes de Alfonso El Sabio. Del Espéculo a las Partidas», en AHDE, 21-22 (1951-52), pp. 345 y ss.

109 Existen numerosas dudas entre los historiadores acerca de muchas de las cuestiones concernientes a la política de Alfonso X a propósito del Fuero Real, el Espéculo y las Partidas, ToMÁS Y VALIENTE, Manual, 233. Sobre la discusión acerca de la vigencia del ius commune, puede consultarse, entre otros, CARLOS PETIT, «Derecho común y derecho castellano», en Revue d'Histoire du Droit, 50 (1982), pp. 157-195; PÉREZ MARTín, A., «Derecho común, derecho castellano, derecho indiano», Rivista Internazionale di Diritto Commune, 5 (1994), pp. 43-89.

110 FR. 4,4,20. Como debe pagar el daño el que diere cusa a él. Quando algun daño viniere á alguno por culpa de otro, ó por su consejo, é por su mandado, sea tenudo de pechar el daño, así como si él mismo lo ficiese: é si por aventura buey, ó can, ó otra bestia qualquier que de su natura debe ser mansa, ficiere daño, ó en heme, ó en bestia, ó en otra cosa, el dueño sea tenudo de emendar el daño, ó de dar el dañador que lo fizo; é si fuere bestia brava por su natura, así como leon, ó oso, o lobo, ó otra bestia semejable, sea tenudo de emendar el daño si no la ató, ó no la guardó así como debía: ó si la ató, é la guardó así como debía, é por ocasión ficiere algun daño, no sea tenudo el dueño de pechar el daño, mas dé el dañador que lo fizo. 


\section{La regulación en las Siete Partidas}

Bajo este nombre se conoce la obra legislativa más importante de toda la historia jurídica española ${ }^{111}$. Constituyen un cuerpo jurídico de mayor alcance que el texto legal del Fuero Real por su planteamiento más doctrinal y su entidad más bien enciclopédica ${ }^{112}$ y puede considerarse el libro jurídico más representativo de la recepción del derecho común en Castilla. Según García y García, el rey Fernando III el Santo y Alfonso X el Sabio usaron la ley visigoda para unificar legislativamente el Reino de Castilla, lo cual preludia y acompaña la recepción del derecho común que se verifica en gran escala en Castilla, cuya colección de las Siete Partidas parece inspirarse en el modelo del Digesto, y el Fuero Real representaría el papel del Código justinianeo. Por lo que respecta al derecho romano, podemos destacar la influencia del mismo, sobre todo en el campo del derecho privado y del penal ${ }^{113}$ en los textos medievales a que aludimos ${ }^{114} \mathrm{y}$ así el texto legal más importante de Alfonso X el Sabio se refiere a la materia objeto de nuestro estudio en una serie de leyes ${ }^{115}$ contenidas en las Partidas 7,15, que lleva la siguiente rúbrica: de los daños que los omes, $o$ las bestias fazen en las cosas de otro de qual natura quier que sean.

111 Pérez Martín, A., «La obra legislativa alfonsina y puesto que en ella ocupan las Siete Partidas», pp. 30 y ss. El historiador García Gallo elaboró y difundió en 1951 y 1963 , una interpretación totalmente innovadora acerca del proceso de elaboración de las Partidas. $\mathrm{Al}$ referirse a este punto, afirma el citado autor que lo que hoy se conoce con el nombre de las Partidas no es una obra de Alfonso X ni de su tiempo, sino de juristas anónimos de finales del siglo XIII y principios del XIV, siendo la citada obra el resultado de un largo y complicado proceso de redacción, cuya primera fase estuvo constituida por el Espéculo. En otro estudio posterior, el mencionado historiador, fija la reelaboración doctrinal del Espéculo y, por tanto, la aparición de las Partidas «acaso hacia 1290», pero de todas formas después de la muerte de Alfonso X, que tuvo lugar en 1284, Tomás y Valiente, F., Manual de historia del derecho español, 3. ${ }^{\mathrm{a}}$ ed. (Madrid, 1981), p. 338.

112 Clavero B., Temas de Historia del Derecho: Derecho de los Reinos (Sevilla, 1990), p. 98. Hay que decir con el autor que las siete partes de que consta la obra abarcan prácticamente todo el sistema de derecho de la época, aunque con frecuencia de forma bastante genérica, sin descender en todos los casos a la regulación concreta de las instituciones jurídicas que contempla.

113 García y García, A., «El derecho común en Castilla durante el siglo XIII». Glossae. Revista de Historia del derecho Europeo, 5-6 (Murcia, 1993-94), p. 55.

${ }_{114} \mathrm{La}$ influencia de las leyes romanas fue puesta ya de relieve por MARTínEZ MARINA, Ensayo crítico sobre la antigua legislación y principales cuerpos legales de León y de Castilla, especialmente sobre el código de las Siete Partidas (Madrid, 1808), reeditado por MARTínEZ CERdos, J., Obras escogidas de Martínez. Marina (Madrid, 1966), pp. 372 y ss. Concretamente en relación a las Partidas V y VI afirma el mencionado autor que los compiladores de estas leyes no hicieron sino extractar algunos textos de las citadas fuentes del Corpus Iuris.

115 Son concretamente las leyes 21, 22 y 23 del título 15. 
En primer lugar, hay que destacar que, al igual que la legislación romana, como se ha visto supra, el texto legal medieval, regula asimismo de forma independiente los daños que produzca el perro, estableciendo la obligación del dueño de pagarlos si se han producido por su culpa y así concretamente en las Partidas 7,15,21116, bajo la rúbrica: como aquel que enrrida el can que muerda a alguno, o espante alguna bestia a sabiendas, deue pechar el daño que le viniere por esta razón, destaca dos supuestos diferentes: 1) en relación con el perro que causa daños en las cosas o a personas, deben ser indemnizados por el dueño del animal, a no ser que fuese provocado por otra persona en cuyo caso ella es la responsable. 2) si algún hombre espanta a alguna bestia (mula, vaca, $u$ otra bestia, dice la ley) y como consecuencia de lo cual se producen daños en el animal (se perdiesse, o se menoscabasse, se fuyes$s e . .$.$) debe responder él mismo del daño causado.$

Asimismo, los daños producidos por determinados animales (bestias) que menciona la ley $22^{117}$, bajo la rúbrica: como es tenudo el señor del cauallo o de otras bestias mansas de pechar el daño que alguna

116 Partidas 7,15, 21. Como aquel que enrrida el can que muerda a alguno, o espante alguna bestia a sabiendas, deue pechar el daño que le viniere por esta razon. Can teniendo algund ome presso si lo soltasse a sabiendas, e le diesse de mano porque fiziesse daño a otro en alguna cosa: o sí anduuiesse el can suelto, e lo enridasse alguno en manera que trauasse del, o le mordiesse, o fiziesse daño a ome, o en alguna otra cosa: tenudo seria el que fiziesse alguna destas cosas sobredichas de fazer emienda del daño que el can fiziesse. Otrosi dezimos que si algund ome espantasse a sabiendas alguna bestia, de manera que la bestia se perdiesse o de menoscabasse: o si por el espanto que le fiziesse se fuyesse, e fuyendo fiziesse ella daño en alguna cosa, tenudo seria el que la ouiesse espantado, de pechar el daño que aceciesse por razon de aquel espanto. Esso mesmo seria quando alguna bestia passasse por alguna puente, e otro la espantasse de manera que cayesse en el agua, e muriesse, o se menoscabasse. Ca en cualquier destas maneras, o en otras semejantes que acaesciesse daño a otro del espanto que ome fiziesse a mula, o a vaca, o a otra bestia, tenudo sería aquel que la espanta de fazer emienda del daño que ende acaesciesse.

117 Partidas 7,15, 22. Como es tenudo el señor del cauallo o de otras bestias mansa de pechar el daño que algun dellas fiziere. mansas son bestias algunas naturalmente: assi como los cauallos, e las mulas, e los asnos, e los bueyes, e los camellos, e los elefantes, e las otras cosas semejantes dellas. Onde si alguna destas bestias fiziere daño a otro por su maldad, o por su costumbre mula que ayan, assi como si fuesse cauallo, o otra bestia de aquellas que usan los omes caualgar, e si ella sin culpa de otro lançasse las coces, o fiziesse daño en alguna cosa: o si fuesse toro, o buey, o vaca, o otra bestia semejante que fuesse mansa por natura, e ella por su maldad sin culpa de otro fiziesse daño en alguna cosa, estonce el señor de qualquier de aquestas bestias que fiziesse el daño, seria tenudo de fazer de dos cosas, la una, o de emendar el daño: o de desamparar la bestia a aquel que el daño rescibiere. Pero si el daño non viniesse por maldad de la bestia mas por culpa de algun ome quel diesse feridas, o la espantasse o la aguijonasse, o le fiziesse otro mal en qualquier manera porque la bestia ouiesse a fazer mal a otro, estonce aquel por cuya culpa auiniesse el daño es tenuda a fazer emienda: e non el señor de la bestia. 
dellas fiziere, da lugar a la responsabilidad del dueño de los mismos si no hay culpa por parte de quien sufrió los daños. Ahora bien el citado dueño tiene también aquí dos posibilidades: una, pagar el daño ocasionado por el animal, dos, entregar el mismo como resarcimiento del daño. Refleja claramente la regulación sobre el particular del derecho romano y la recepción del citado derecho en el texto medieval alfonsino. Por otra parte, establece además la citada ley que si el daño que causa el animal se produce porque alguien hiere, espanta o aguijonea al animal, en este caso no es responsable el dueño del mismo.

La ley $23^{118}$ en la misma sede de las Partidas (Partidas, 7,15), tiene relación con los daños causados por los animales bravos (bestias brauas) y lleva la siguiente rúbrica: como aquel que tiene el leon, o osso, o otra bestia braua en su casa deue pechar el daño que fiziere a otro.

Comienza la citada ley estableciendo la obligación del dueño de guardar los citados animales, evitando que ocasionen daños, en caso de que se produzcan contempla el texto legal una serie de supuestos. 1) Que los animales causen daño en cosa ajena: el dueño pagará el doble de los daños que se hayan producido. 2) Que causen daños a una persona: el dueño ha de pagar una serie de gastos que se le ocasionen, así como el trabajo que no pudo realizar a consecuencia de la herida que le ocasionó el animal. 3) Otra posibilidad que contempla la ley es la muerte de una persona, estableciendo para este supuesto el pago de dozientos marauedis de oro: la meytad a los herederos del muerto, e la otra meytad a la camara del Rey. 4) Además, si el herido no fallece mas fincasse lisiado de algun miembro, deberá indemnizar la cuantía que establezca el juez.

118 Partidas 7,15,23. Como aquel que tiene el leon, o osso, o otra bestia braua en su casa deue pechar el daño que fiziere a otro. Leon o Onza, o Leon pardo, o Osso, o Lobo Crual, o Gineta, o Serpiente, o otras bestias, que son brauas de natura, teniendo algund ome en su casa deuela guardar, e de tener pressa, de manera que non faga daño a ninguno. E si por auentura non la guardassen assi, efiziese daño en alguna cosa de otro, deuelo pechar doblado el señor de la bestia a aquel que lo rescibio. E si alguna destas bestias fiziesse daño en la persona de algun ome, de manera que lo llagasse, deuelo fazer guarescer el señor de la bestia, comprando las melezinas, e pagando al maestro que lo guarescere de los suyo, e deue pensar del llagado fasta que sea guarido. E demas desto deuele pechar las obras que perdio desde el dia que rescibio el daño fasta el dia que guarescio, $e$ aun los menoscabos, que recisbio en otra manera por razon de aquel daño, que rescibio de la bestia E si muriere de aquellas llagas quel fizo, deue pechar por ende aquel cuya era la bestia, dozientos de oro: la meytad a los herederos del muerto, e la otra meytad a la camara del Rey. E si por auentura non muriesse, mas fincasse lisiado de algun membro, deuele fazer emienda de la lision según aluedrio del judgador acatando quien es aquel que rescibio este mal, e en qual miembro. 